\title{
Some aspects of the aetiology, diagnosis and treatment of infertility in the bitch
}

\author{
Jean P. Renton, C. D. Munro, R. H. Heathcote and S. Carmichael \\ University of Glasgow Veterinary School, Bearsden, Glasgow G61 1QH, U.K.
}

\begin{abstract}
Summary. The nature of the infertility in 19 bitches was investigated: 10 animals were considered to be normal on the basis of their sexual behaviour, vaginal cytology and plasma oestrogen and progesterone concentrations. Successful conception and whelping occurred for 6 of the 10 bitches. The previous apparent infertility was probably attributable to defective mating management by the owners. Although follicular development and ovulation occurred in 4 of the remaining bitches, oestrus was not exhibited: AI resulted in 3 conceptions. The other 5 animals exhibited only some of the normal characteristics of pro-oestrus.

Another group of 10 anoestrous bitches (normal and pathological) was treated with PMSG or stilboestrol. PMSG induced follicular development in 5 of 6 bitches treated. The magnitude of the induced plasma oestrogen peak varied considerably. Delay in the initiation of oestrous behaviour occurred relative to the plasma gonadal steroid pattern in 2 of the 3 bitches that showed oestrus. Stilboestrol induced a sequence of behavioural changes and plasma steroid concentrations and patterns similar to those found in the normal oestrous bitch, but none conceived.
\end{abstract}

\section{Introduction}

Although a great deal has been published concerning the behavioural, hormonal and vaginal cytological changes of the reproductive cycle of the bitch (Christie \& Bell, 1972; Concannon, Hansel \& Visek, 1975; Edqvist, Johansson, Kasström, Olsson \& Richkind, 1975; Roszel, 1977; Wildt, Panko, Chakraborty \& Seager, 1979), little comparable information exists regarding these parameters in the clinically infertile animal. Appreciation of these changes and their interrelationships in both normal and abnormal bitches, besides possibly elucidating certain aetiological factors restricting fertility, is a prerequisite to their employment as diagnostic aids and for selection and monitoring of the effectiveness of appropriate treatments. Drawing an analogy from recent developments in other species of domestic animals, it is likely that the availability of techniques to induce follicular development and ovulation would facilitate treatment of at least a proportion of non-infectious cases of infertility in the bitch. Limited information is available on the use of stilboestrol (Hancock \& Rowlands, 1949), pituitary gonadotrophins (Andersen \& Simpson, 1973) and non-pituitary gonadotrophins (Hancock \& Rowlands, 1949; Bell \& Christie, 1971) to bring about oestrus in anoestrous bitches. Data on the physiological and endocrinological changes characterizing the period around ovulation in the normal bitch permit a more detailed monitoring of the response of anoestrous bitches to these treatments, and observations on these aspects are given in the present paper. 


\section{Investigation of infertile bitches}

\section{Materials and methods}

Animals. The 19 animals were 2-7 years of age and were of a variety of breeds. All bitches were referred for investigation either because although mated on a number of different occasions they had failed to conceive, or because they had failed to demonstrate normal oestrus. Information on previously employed methods of detecting oestrus, the inter-oestrous intervals and whether or not the animal had previously had a litter was obtained from the owner. Bitches were admitted for investigation when their owners thought them to be in early pro-oestrus.

Investigation of sexual behaviour. For $5 \mathrm{~min}$, twice daily, each bitch was allowed to run freely with a mature stud dog or a vasectomized aduit dog. Observations were made on the proceptivity of the bitch and the response of the male to the female. Bitches were considered to be in pro-oestrus when the male was very attracted but the bitch was not receptive. Oestrus was characterized by the bitch adopting a rigid stance, with her tail held to the side, and allowing mounting by the male.

Vaginal cytology. Over the period of investigation, smears were made every second day from material taken from the lumen of the anterior vagina. The smears were fixed in methanol and stained with Giemsa. Nucleated epithelial cells, cornified epithelial cells, red blood corpuscles and white blood corpuscles were assessed as being present on a scale ranging from absent $(-)$, through sparse $(+)$ to abundant $(++++)$. In the normal pro-oestrous bitch red blood cells are predominant in the vaginal smear, with increasing numbers of cornified cells appearing in late pro-oestrus. During oestrus, cornified epithelial cells are the commonest cell type and white blood cells are then found after the period of maximum vaginal cornification.

Plasma concentrations of progesterone and total oestrogens. Plasma concentrations of progesterone and total oestrogens were determined using previously described radioimmunoassay techniques (Munro, Renton \& Butcher, 1979). Addition of known amounts of progesterone $(0 \cdot 2-1.0 \mathrm{ng})$ and oestradiol- $17 \beta(20-100 \mathrm{pg})$ to plasma from an ovariectomized bitch gave correlation coefficients (amount estimated:amount present) of 0.9821 and 0.9734 respectively. Within- and between-assay variations were 11 and $17 \%$ for progesterone and 4 and $12 \%$ for total oestrogens. Minimum detectable amounts in the assays were $0.3 \mathrm{ng}$ progesterone $/ \mathrm{ml}$ and $7 \mathrm{pg}$ total oestrogens $/ \mathrm{ml}$. Blood samples from the bitches were taken at appropriate intervals depending on the associated behavioural and vaginal cytological changes.

Mating of bitches. Natural mating or artificial insemination were carried out using proven sires or semen from such animals. Artificial insemination was performed following the recommendations of Seager \& Fletcher (1973) by placing freshly collected first and second fractions of an ejaculate into the anterior vagina.

\section{Results}

Of the 19 bitches investigated, 10 were considered to be normal because the sequences of behavioural, vaginal cytological and hormonal changes were similar to those previously recorded in normal bitches. Typical findings for one bitch are given in Table 1(A). These 10 apparently normal bitches were mated naturally on the day following the first day of standing oestrus and in some animals again 2 days later; 6 animals conceived and produced live pups and 4 failed to conceive.

Four of the bitches were classified as demonstrating abnormal behaviour, in the form of silent ovulations, in that although the vaginal cytology and plasma steroid concentrations in the period around ovulation were normal, the bitches refused to allow mounting and intromission. Table 1(B) gives the observations for one such animal. Artificial insemination was carried out on these 4 bitches on the day following peak plasma oestrogen concentrations and when cornified epithelial cells were abundant in the vaginal smear. Of the 4 bitches inseminated, 3 conceived and produced normal young. 
Table 1. Changes in bitches showing (A) normal behaviour; (B) abnormal behaviour; and (C) abnormal ovarian function

\begin{tabular}{|c|c|c|c|c|c|c|}
\hline \multirow{3}{*}{$\begin{array}{c}\text { Days } \\
\text { from } \\
\text { admission }\end{array}$} & \multirow{2}{*}{\multicolumn{2}{|c|}{ Vaginal cytology* }} & \multicolumn{2}{|c|}{ Sexual behaviour } & \multirow{3}{*}{$\begin{array}{c}\text { Plasma } \\
\text { oestrogens } \\
(\mathrm{pmol} / \mathrm{l})\end{array}$} & \multirow{3}{*}{$\begin{array}{l}\text { Plasma } \\
\text { progesterone } \\
(\mathrm{nmol} / \mathrm{l})\end{array}$} \\
\hline & & & \multirow{2}{*}{$\begin{array}{l}\text { Response of } \\
\text { ot to } \sigma^{2}\end{array}$} & \multirow{2}{*}{$\begin{array}{c}\text { Response of } \\
\delta \text { to } \$\end{array}$} & & \\
\hline & $\mathbf{R B C}$ & CEC & & & & \\
\hline \multicolumn{7}{|c|}{ A. Shetland collie bitch whelping 5 pups } \\
\hline 0 & ++++ & ++ & Flirting & Attracted & 76 & 1 \\
\hline 1 & ++++ & ++ & Flirting & Attracted & 78 & 2 \\
\hline 2 & $t+t+$ & +++ & Flirting & Attracted & NC & 5 \\
\hline 3 & +++ & +++ & Flirting & Attracted & 83 & 1 \\
\hline 4 & ++ & ++++ & Flirting & Attracted & 132 & 3 \\
\hline 6 & +++ & ++ & Flirting & Attracted & 95 & 3 \\
\hline 7 & ++ & ++++ & Flirting & Attracted & 144 & 4 \\
\hline 8 & + & ++++ & Flirting & Attracted & 170 & 1 \\
\hline $11 \dagger$ & NC & NC & $\mathrm{NC}$ & $\mathrm{NC}$ & NC & NC \\
\hline 13 & ++ & $+++t$ & NC & NC & 46 & 25 \\
\hline 16 & ++ & ++++ & NC & $\mathrm{NC}$ & 53 & 58 \\
\hline \multicolumn{7}{|c|}{ B. Pyrenean Mountain bitch whelping 10 pups } \\
\hline 0 & +++ & +++ & Rejected & Attracted & $\mathrm{NC}$ & 3 \\
\hline 1 & ++ & +++ & Rejected & Attracted & 210 & 4 \\
\hline 4 & + & ++++ & Rejected & Attracted & 299 & 3 \\
\hline $7 \dagger$ & + & ++++ & Rejected & Attracted & 53 & 20 \\
\hline $8 \dagger$ & + & ++++ & Rejected & Attracted & 25 & 21 \\
\hline $9+$ & $\mathrm{NC}$ & $\mathrm{NC}$ & $\mathrm{NC}$ & NC & $\mathrm{NC}$ & $\mathrm{NC}$ \\
\hline 15 & - & ++ & $\mathrm{NC}$ & $\mathrm{NC}$ & NC & 60 \\
\hline \multicolumn{7}{|c|}{ C. Retriever bitch } \\
\hline 0 & + & ++ & Flirting & Attracted & 68 & 6 \\
\hline 1 & + & ++ & Flirting & Attracted & 57 & NC \\
\hline 2 & + & +++ & Rejected & Attracted & 63 & 5 \\
\hline 3 & + & ++ & Rejected & Not interested & 73 & 4 \\
\hline 4 & NC & NC & Rejected & Not interested & 93 & $\mathrm{NC}$ \\
\hline 6 & NC & NC & Flirting & Attracted & 73 & 8 \\
\hline $7 \ddagger$ & $\mathrm{NC}$ & $\mathrm{NC}$ & $\mathrm{NC}$ & $\mathrm{NC}$ & 77 & 6 \\
\hline 22 & NC & NC & NC & NC & 56 & 7 \\
\hline
\end{tabular}

RBC, red blood corpuscles; CEC, cornified epithelial cells; NC, not checked.

* Scored from - to ++++ (see text).

$\dagger$ Mated.

$\ddagger$ Treated with 500 i.u. hCG.

The remaining 5 animals were considered to have abnormal ovarian function. All 5 bitches exhibited a degree of attractiveness to the male, and had some vaginal cytological changes indicative of pro-oestrus, but subsequent smears failed to demonstrate the normal progression of cornification associated with advancing oestrus. Results from one animal are given in Table 1(C). Three of the animals were injected subcutaneously with 500 i.u. hCG (Chorulon: Intervet, Cambridge, U.K.). In none of these cases was administration of this hormone followed by permanent cessation of the symptoms of prolonged attractiveness to males, vulvar swelling with or without vulvar bleeding. These 3 bitches and 1 other were ovariohysterectomized. The 5th bitch failed to conceive to a forced mating when returned to the owner after study.

\section{Induction of oestrus and ovulation}

\section{Materials and methods}

Animals. The bitches included 7 normal animals ( 3 West Highland terriers, 2 foxhounds and 2 Alsatians). In addition 3 clinical cases ( 2 chows and 1 Doberman) that had failed to exhibit 
oestrus over a prolonged period ( $>18$ months) were studied. All bitches at the beginning of the investigation were considered to be in anoestrus on the basis of the interval from their previous oestrus, their current unattractiveness to males, their vaginal cytology and the presence of basal plasma concentrations of progesterone and oestrogens.

Treatments. Irrespective of their body weight, increasing quantities $(0.05-1 \mathrm{mg})$ of the synthetic oestrogen, stilboestrol dipropionate (May \& Baker, Dagenham, U.K.) in oil were administered at 4-5 day intervals to the 3 normal West Highland terriers and the abnormal Doberman bitch following the regimen described by Hancock \& Rowlands (1949).

The animals detailed in Table 2 were each given a daily subcutaneous injection of 500 i.u. PMSG (Folligon: Intervet) for a maximum of 10 days in a modification of the scheme proposed by Bell \& Christie (1971).

Table 2. Responses of 6 anoestrous bitches (see text) to treatment with 500 i.u. PMSG daily

\begin{tabular}{llcccc}
\hline Breed & $\begin{array}{c}\text { Type of } \\
\text { anoestrus* }\end{array}$ & $\begin{array}{c}\text { Duration of } \\
\text { treatment } \\
\text { (days) }\end{array}$ & $\begin{array}{c}\text { Days from 1st } \\
\text { injection to } \\
\text { onset of oestrus }\end{array}$ & $\begin{array}{c}\text { Pays from } \\
\text { 1st injection }\end{array}$ & $\begin{array}{c}\text { Conc. } \\
\text { (pmol/l) }\end{array}$ \\
\hline Foxhound & Normal & 7 & 11 & 5 & 600 \\
Foxhound & Normal & 8 & 13 & 8 & 557 \\
Chow & Abnormal & 5 & Not shown & 8 & 392 \\
Chow & Abnormal & 10 & Not shown & 16 & 600 \\
Alsatian & Normal & 10 & 13 & 10 & 345 \\
Alsatian & Normal & 10 & Not shown & No distinct peak & 115 \\
\hline
\end{tabular}

* Normal = normal oestrous cycle and anoestrous period; abnormal = absence of normal oestrus for $>18$ months.

The vaginal cytology, behaviour and plasma hormone concentrations were investigated as described above.

\section{Results}

All the bitches treated with stilboestrol responded in a similar way (see Text-fig. 1). After the last stilboestrol injection, plasma total oestrogen concentrations rose above the values found before treatment. Thereafter both the pattern and peak concentration of plasma oestrogens were similar to those found in normal bitches during pro-oestrus. All 4 bitches demonstrated behavioural oestrus around the time of maximum oestrogen concentration. During treatment substantial numbers of cornified cells appeared in the vaginal smears and these cells persisted

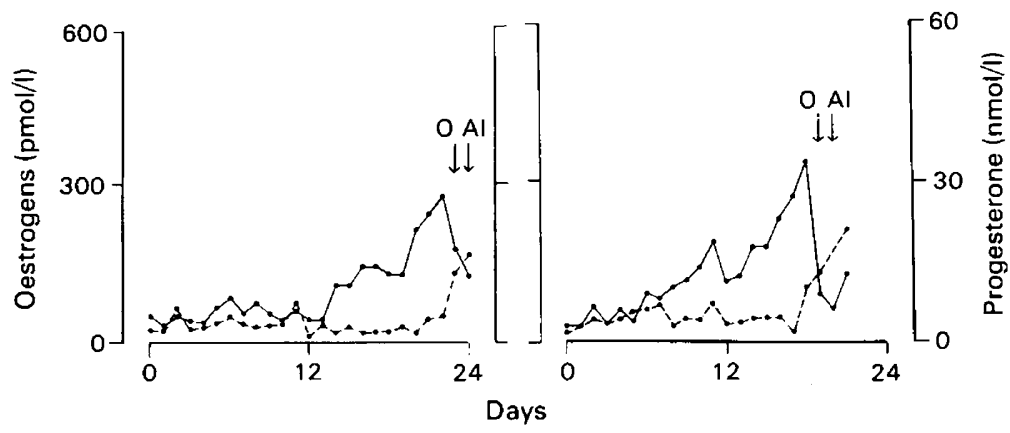

Text-fig. 1. Total oestrogen (-) and progesterone (---) concentrations in plasma of 2 West Highland terriers treated with stilboestrol (Day 0 ). $\mathrm{O}=$ oestrus. The bitches were artificially inseminated when indicated. 
while plasma oestrogens subsequently increased in concentration. Ovulation was considered to have occurred in all animals on the basis of sustained increase in plasma progesterone concentrations after the peak of plasma oestrogens. However, although 3 of the bitches were artificially inseminated and 1 was mated naturally 1 day after the onset of oestrus, none conceived.

Table 2 shows the results from the 6 bitches treated with PMSG. Only 3 of the bitches demonstrated behavioural oestrus. There appeared to be no consistent relationship between the amount of hormone injected and the magnitude or timing of the peak concentration of plasma oestrogens. In the 3 bitches showing oestrous behaviour, the onset of such behaviour appeared to be dissociated from the time of peak plasma concentration of oestrogens. With the exception of the Alsatian that did not show a distinct peak of plasma oestrogens following treatment, all animals were considered to have ovulated on the basis of increased plasma progesterone values after treatment.

\section{Discussion}

The results from the 19 infertile bitches are of interest for several reasons. The most outstanding feature is that the majority of bitches presented with this kind of abnormality were those kept as pets and more than half were shown to be normal with reference to their vaginal cytological and gonadal steroid changes throughout pro-oestrus and oestrus. Confirmation of the normality of many of the bitches was demonstrated by pregnancy after controlled mating. There are 2 possible reasons why these animals were presented as apparently infertile. Firstly, most pet owners wishing to mate their bitches seek advice from breeders of bitches of the same breed and mating may be recommended at a particular time after the beginning of pro-oestrus, for example 10 days from the onset of vulvar bleeding, irrespective of whether or not the bitch has demonstrated true signs of oestrus. We believe that, as a consequence of this approach, many such bitches are not mated naturally but are force mated because they are not in oestrus. When admitted for investigation these bitches were only mated when they themselves demonstrated at one of the twice daily tests with the dog that they were ready for mating. It could well be that in bitches, as with all other domestic species, the inability to detect oestrus is one of the main causes of infertility. The second factor is that most bitches kept as pets do not have free access to the male during the pro-oestrous period. When the bitches were admitted to hospital for investigation they were allowed free access to a dog at least twice a day during pro-oestrus. Their behaviour at that time was flirting, attractiveness and being attracted to the male. It may be that this foreplay, that can only be initiated in response to the attentions of a dog during pro-oestrus, is an integral part of the physiological mechanisms regulating the ultimate expression of acceptance behaviour of the female.

Under the conditions we used to assess sexual behaviour of the infertile bitches, some of the animals demonstrated abnormal behaviour in that they would not allow the male dog to mount and achieve intromission although vaginal cytology and plasma gonadal steroid concentrations indicated that they should have been in standing oestrus. Oestrogen and progesterone have been considered necessary for normal proceptivity of the oestrous bitch and attractiveness to the male (Beach \& Merari, 1970; Concannon, Weigand, Wilson \& Hansel, 1979). Our results which indicate no obvious abnormalities in the pattern or concentrations of either of these hormones in the plasma of bitches studied may reflect an inability of neural centres governing proceptivity to respond to what appeared to be a normal stimulus.

Treatments with stilboestrol or PMSG resulted in an increase in plasma oestrogen concentrations. Follicular growth also occurred and ovulation took place presumably in response to direct gonadotrophic stimulation in the PMSG-treated bitches and by stimulating the synthesis and release of pituitary gonadotrophins and/or by modifying the responsiveness of the 
ovaries to these hormones in the stilboestrol-treated animals. The unpredictable nature of the response of animals to the PMSG treatment used in this study does, we feel, preclude the use of this method as a means of inducing normal follicular growth, ovulation and oestrus in the anoestrous bitch, but a regimen of small doses of stilboestrol could be a valuable adjunct in the treatment of infertile bitches.

\section{References}

Andersen, A.C. \& Simpson, M.E. (1973) The Ovary and Reproductive Cycle of the Dog (Beagle). Geron-X Inc., Los Altos.

Beach, F.A. \& Merari, A. (1970) Coital behaviour in dogs. V. Effects of estrogen and progesterone on mating and other forms of social behaviour in the bitch. J. comp. Physiol. Psychol. Monograph 70, 1-22.

Bell, E.T. \& Christie, D.W. (1971) Gonadotrophin induced ovulation in the bitch. In Proc. 7th Int. World Congr. Fert. Steril., Tokyo, Abstr. No. 89. Eds T. Hasegawa, M. Hayashi, F. J. G. Ebling \& I. W. Henderson. Excerpta Medica (ICS No. 234), Amsterdam.

Christie, D.W. \& Bell, E.T. (1972) Studies on canine reproductive behaviour during the normal oestrous cycle. Anim. Behav. 20, 621-631.

Concannon, P.W., Hansel, W. \& Visek, W.J. (1975) The ovarian cycle of the bitch: plasma estrogen and progesterone. Biol. Reprod. 13, 112-121.

Concannon, P.W., Weigand, N., Wilson, S. \& Hansel, W. (1979) Sexual behaviour in ovariectomised bitches in response to estrogen and progesterone treatments. Biol. Reprod. 20, 799-809.

Edqvist, L.-E., Johansson, E.D.B., Kasström, H., Olsson, S.-E. \& Richkind, M. (1975) Blood plasma levels of progesterone and oestradiol in the dog during the oestrous cycle and pregnancy. Acta endocr., Copenh. 78, 554-564.

Hancock, J.L. \& Rowlands, I.W. (1949) The physiology of reproduction in the dog. Vet. Rec. 61, 771-779.

Munro, C.D., Renton, J.P. \& Butcher, R. (1979) The control of oestrous behaviour in the mare. J. Reprod. Fert., Suppl. 27, 217-227.

Roszel, J.F. (1977) Normal canine vaginal cytology. The Veterinary Clinics of North America 7, 667-681.

Seager, S.W.J. \& Fletcher, W.S. (1973) Collection, storage and insemination of canine semen. $L a b$. Anim. Sci. 22, 177-182.

Wildt, D.E., Panko, W.B., Chakraborty, P.K. \& Seager, S.W.J. (1979) Relationship of serum estrone, estradiol-17 $\beta$ and progesterone to LH, sexual behavior and time of ovulation in the bitch. Biol. Reprod. 20, 648-658.

Received 25 February 1980 